\title{
EDITORIAL
}

\section{La necesidad de repensar nuestra Ingeniería de Petróleos}

Son considerables los cambios que suceden en este mundo dinámico; transformaciones que nos hacen pensar nuevamente en la razón de ser de la ingeniería de petróleos.

Por tal circunstancia y considerando la trayectoria del programa de Ingeniería de Petróleos de la Fundación Universidad de América, en primer lugar debemos preguntarnos qué es aún válido y qué deberíamos actualizar y ajustar a las realidades en las que vivimos actualmente.

Si bien hace algún tiempo nos centramos en los cuatro grandes pilares de la industria: exploración, producción, transporte y comercialización, es necesario incorporar las nuevas disciplinas y tecnologías para así formar parte y gerenciar los proyectos que hoy en día se desarrollan en el país.

Estas nuevas áreas del conocimiento son apoyos esenciales para sincronizar las acciones con una dirección acertada de la industria. Algunas de estas disciplinas están relacionadas con el apoyo y la sensibilización de las comunidades circundantes al proyecto; el manejo de la normatividad legal existente, que se presenta cambiante y retadora; el uso de materias relacionadas con hidrocarburos no convencionales, como el gas de esquisto (shale gas) o el gas asociado al carbón, entre otras.

Estos cambios son requeridos a corto plazo; pero deben perdurar en el tiempo y, ante todo, evidenciar que aportan de manera contundente al correcto direccionamiento de la industria de los hidrocarburos, que, como bien es sabido, tiene una participación importantísima en la macroeconomía nacional.

Estas razones son suficientes para exhortar y lograr el concurso de todos los actores que participamos en esta industria; especialmente de nosotros, los directivos, docentes y estudiantes, que desde la academia gestamos el conocimiento requerido para la divulgación y aplicación de los cambios necesarios.

La investigación es la pieza fundamental a la hora de propiciar iniciativas que permitan alcanzar estos propósitos, y desde esta revista estaremos prestos a presentar estos desarrollos y avances concebidos desde nuestra querida institución.

José Humberto Cantillo Silva

Director Programa Ingeniería de Petróleos Fundación Universidad de AmÉrica 